\title{
The Adaptation of Hydrogen Ion Excretion Associated with Nephron Reduction in Post-transplant Patients
}

\author{
James C. M. Chan ${ }^{[5]}$, Carl M. Grushimin, Mohammad Malekzadeh, \\ Ori Better, and Richard N. Fine \\ Renal Division, Department of Medicine, Children's Hospital of Los Angeles, University of Southern California, \\ Los Angeles, California, USA, and Department of Nephrology, Rambam Hospital, Haifa, Israel
}

\section{Extract}

The compensatory growth of the single and transplanted kidney is demonstrated by the improvement of glomerular filtration rate (GFR) of the single kidney to achieve $50-90 \%$ of the normal value. The compensatory renal tubular acid excretion is also studied. It is clearly demonstrated that in response to a standard ammonium chloride load $\left(75 \mathrm{mEq} / \mathrm{m}^{2}\right)$ systemic acidosis $\left(\mathrm{tCO}_{2}<16 \mathrm{mEq} / \mathrm{liter}\right)$ occurs uniformly at 300-400 min but maximal renal acid excretion $(98 \pm 12$ and $76 \pm 17 \mu \mathrm{Eq} / \mathrm{min} /$ $1.73 \mathrm{~m}^{2}$ ) occurs in the normal and single kidney subjects, respectively, at $300-400$ min, whereas, for the transplant subjects, maximal acidifications of $72 \pm 34$ and $74 \pm 26 \mu \mathrm{Eq} / \mathrm{min} / 1.73 \mathrm{~m}^{2}$ are achieved at 800 and $1,400 \mathrm{~min}$ for live-related and cadaveric allografts, respectively. The slower and suboptimal renal response accounts for the persistence of metabolic acidosis in the transplant population.

The studies document that the important limiting factor is the reduction in glomerular filtration rate in the transplant subjects. When the low net acid excretion in the two transplant groups are factored by GFR, they become comparable with the control (donor) group as well as the normal group $(P>0.95)$, i.e., each remaining nephron is excreting acid normally (or supernormally) and is supportive of the "intact nephron" hypothesis.

The data show a marked difference in urinary $\mathrm{pH}$ during acidosis between the two transplant groups: $50 \%$ of the cadaveric allografts have an inability to lower urine $\mathrm{pH}$ below 5.4 compared with $10 \%$ only of the live-related allografts which show such a defect. This would imply that cadaver allografts are more susceptible to an acute acid load.

\section{Speculation}

The ischemia sustained at the time of transplantation results in acute tubular damage and proportionate lowering of the glomerular filtration rate which account for the impaired acidification capacity in the kidney allografts. It is also possible that circulatory damage to the glomeruli may occur in the transplantation process. It is even possible that intrarenal circulation may be altered by either transplantation or nephrectomy; although, admittedly, this last possibility seems quite unlikely. It is open to speculation what effect the age difference between the donors and the recipients may have on their different responses to acute metabolic acidosis. 


\section{Introduction}

Previous studies have indicated that cadaveric renal allografts fail to respond adequately to an ammonium chloride load when compared with allografts from normal adults $[2,3,11]$. This defective renal acidification has been ascribed to severe acute tubular necrosis sustained at the time of transplantation, to rejection (acute and chronic), and to incomplete renal tubular acidosis $[2,3,11]$.

Allografts from live-related donors have a shorter ischemia time and sustain less tubular injury at transplantation than those from cadaver donors. Consequently, by comparing the response to an $\mathrm{NH}_{4} \mathrm{Cl}$ load in recipients of live-related and cadaveric allografts the relation of the acidification defect to acute tubular necrosis could be established. Furthermore, by investigating recipients at various times post-transplantation the transience or permanence of the defect could be discerned and the degree of recovery detected. In addition, the response of a normal adult with two kidneys to an $\mathrm{NH}_{4} \mathrm{Cl}$ load may differ from that of an adult with a single kidney, the latter being more appropriate to use for comparison with allograft recipients.

The purpose of this study was (1) to compare the renal tubular and glomerular function in four populations: normal adults with two kidneys, unilaterally nephrectomized adult allograft donors who served as control subjects, recipients of live-related donor allografts, and recipients of cadaveric donor allografts; (2) to investigate renal function in the above recipients at various times after transplantation.

\section{Methods}

\section{Subjects}

Three unrelated healthy adult males aged 28-32 years served as normal subjects. Five healthy adults, two males and three females, aged $30-45$ years, who donated a kidney served as control subjects. The unilateral nephrectomies on control subjects were performed 180-1148 days (mean 408 days) before the study. Ten live-related allograft recipients and $15 \mathrm{ca}-$ daver allograft recipients were studied. Their age, sex, and time post-transplantation are shown in Table I. All subjects were studied in the air-conditioned ward of the Clinical Research Center, Children's Hospital of Los Angeles.
Table I. Clinical data for control subjects, live-related, and cadaveric transplants ${ }^{1}$

\begin{tabular}{|c|c|c|c|c|c|}
\hline \multirow{2}{*}{$\begin{array}{l}\text { Sub- } \\
\text { jects }\end{array}$} & \multicolumn{2}{|c|}{ Age } & \multirow{2}{*}{ Sex } & \multirow{2}{*}{$\begin{array}{l}\text { Days post- } \\
\text { transplant }\end{array}$} & \multirow{2}{*}{ Primary disease } \\
\hline & $\mathrm{Yr}$ & Mo & & & \\
\hline \multicolumn{6}{|c|}{ Control (donor) subjects } \\
\hline 1 & 25 & $11 / 12$ & M & 180 & None \\
\hline 2 & 46 & 0 & $\mathrm{~F}$ & 217 & None \\
\hline 3 & 37 & $6 / 12$ & $\mathrm{~F}$ & 227 & None \\
\hline 4 & 32 & $3 / 12$ & M & 270 & None \\
\hline 5 & 40 & $1 / 12$ & $\mathrm{~F}$ & 1,148 & None \\
\hline \multicolumn{6}{|c|}{ Live-related transplant } \\
\hline 6 & 13 & $10 / 12$ & $\mathrm{~F}$ & 35 & Nephritis \\
\hline 7 & 14 & $11 / 12$ & M & 42 & Chronic GN \\
\hline 8 & 14 & $1 \% 12$ & $\mathrm{~F}$ & 43 & $\begin{array}{l}\text { Membraneous } \\
\text { GN }\end{array}$ \\
\hline 9 & 13 & $8 / 12$ & $\mathrm{~F}$ & 76 & Chronic GN \\
\hline 10 & 6 & $9 / 12$ & $\mathrm{~F}$ & 78 & Chronic GN \\
\hline 11 & 17 & $4 / 12$ & $\mathrm{~F}$ & 113 & Chronic GN \\
\hline 12 & 7 & $2 / 12$ & $\mathrm{~F}$ & 221 & $\begin{array}{c}\text { Oligomegalo- } \\
\text { nephronia }\end{array}$ \\
\hline 13 & 14 & $2 / 12$ & $\mathrm{~F}$ & 707 & Nephrosis \\
\hline 14 & 11 & $9 / 12$ & M & 872 & Nephrosis \\
\hline 15 & 10 & $10 / 12$ & M & 1,595 & Chronic GN \\
\hline \multicolumn{6}{|c|}{ Cadaveric transplant } \\
\hline 16 & 18 & $2 / 12$ & M & 50 & $\begin{array}{l}\text { Familial ne- } \\
\text { phritis }\end{array}$ \\
\hline 17 & 15 & $3 / 12$ & $\mathrm{~F}$ & 54 & $\begin{array}{c}\text { Obstructive } \\
\text { uropathy }\end{array}$ \\
\hline 18 & 10 & $1 \% / 2$ & $\mathrm{~F}$ & 112 & Chronic GN \\
\hline 19 & 10 & $9 / 12$ & M & 126 & $\begin{array}{c}\text { Obstructive } \\
\text { uropathy }\end{array}$ \\
\hline 20 & 15 & $5 / 12$ & $\mathrm{~F}$ & 128 & Chronic GN \\
\hline 21 & 10 & $8 / 12$ & F & 198 & Nephritis \\
\hline 22 & 10 & $5 / 12$ & M & 340 & $\begin{array}{l}\text { Infantile poly- } \\
\text { cystic disease }\end{array}$ \\
\hline 23 & 14 & $6 / 12$ & $\mathrm{~F}$ & 397 & Chronic GN \\
\hline 24 & 13 & $2 / 12$ & $\mathrm{~F}$ & 509 & Chronic GN \\
\hline 25 & 18 & $3 / 12$ & $\mathrm{~F}$ & 522 & Chronic GN \\
\hline 26 & 14 & $6 / 12$ & M & 638 & $\begin{array}{c}\text { Obstructive } \\
\text { uropathy }\end{array}$ \\
\hline 27 & 18 & 0 & M & 743 & Chronic GN \\
\hline 28 & 16 & $7 / 12$ & $\mathrm{~F}$ & 763 & Chronic GN \\
\hline 29 & 21 & $3 / 12$ & M & 1,065 & Membranopro- \\
\hline 30 & 15 & $2 / 12$ & $\mathrm{~F}$ & 1,249 & liferative \\
\hline
\end{tabular}

${ }^{1} \mathrm{M}$ : male; $\mathrm{F}$ : female; GN : glomerulonephritis.

\section{Procedures}

A total of 33 separate studies were carried out. All subjects were admitted to the Clinical Research Center the previous afternoon for the usual hospital dinner and to obtain a complete 12-hr urine collection for creatinine clearance and the control urine before $\mathrm{NH}_{4} \mathrm{Cl}$ acidification. On admission, physical examination, chemi- 
cal analyses, hemoglobin, hematocrit, leukocyte count, urinalysis, and chest $\mathrm{x}$-ray were done to ascertain absence of acute illness. In the first five studies breakfast was withheld but because of the nausea induced by the ammonium chloride on an empty stomach, a light breakfast before ammonium chloride loading was permitted in all subsequent studies. For the first $8 \mathrm{hr}$ of the study, the patients reclined comfortably in bed and no food was allowed except free access to dextrose water; after that they were allowed to stroll around the ward and were served the usual hospital meals.

At 7:00 AM on the day after admission the 12-hr control urine collection ended and aliquots of the urine were obtained for determinations of net acid, amino acid, creatinine, sodium, potassium, calcium, magnesium, inorganic phosphorus, and chloride. Lugol's solution ( 6 drops orally) was administered before the ${ }^{125}$ I sodium iothalamate clearance. At 7:30 AM a specimen of arterialized capillary blood was obtained for control acid-base status, and venous blood for sodium, potassium, calcium, magnesium, chloride, phosphate, creatinine, blood urea nitrogen, and ${ }^{125} \mathrm{I}$ background determinations. During the succeeding $5 \mathrm{hr}$ fluids were administered orally at the rate of $20 \mathrm{ml} / \mathrm{kg}$ to ensure a good urine flow for the ${ }^{125} \mathrm{I}$ clearance study. Subsequently the urine output was replaced, $\mathrm{v} / \mathrm{v}$, with clear fluids.

At 8:00 AM (zero time) ammonium chloride (gelatin coated, not enteric coated, tablet) was given orally in the dosage of $75 \mathrm{mEq} / \mathrm{m}^{2}$ during a 60 -min period. The bladder was emptied at 9:00 AM. Ten microcuries of sodium iothalamate ${ }^{125} \mathrm{I}$ were injected intravenously at 9:00 AM. Urine was collected at hourly intervals and blood specimens were obtained at the midpoint of the urine collection period for ${ }^{125} \mathrm{I}$ determinations. Ali-
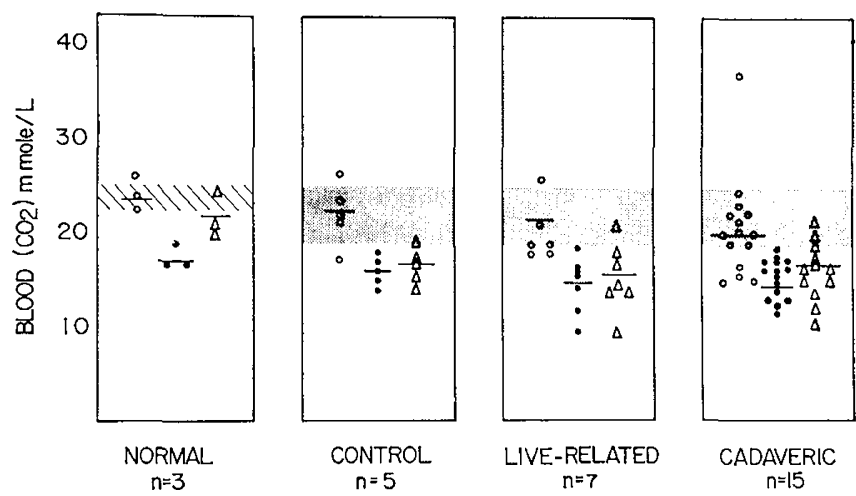

Fig. 1 . Blood total carbon dioxide determinations at zero time (O), $360 \mathrm{~min}(\bullet)$, and 1,920 $\mathrm{min}(\triangle)$ after ammonium chloride $\left(75 \mathrm{mEq} / \mathrm{m}^{2}\right)$ ingestion. quots of the hourly urine collection were utilized for determinations of net acid, sodium, potassium, calcium, magnesium, chloride, and phosphorus. Subsequent to these hourly collections, urine was collected at one 3-hr period, two 4-hr periods, and two 8-hr periods, for a total of $32 \mathrm{hr}$ after ammonium chloride administration. All of these collections were similarly analyzed as the control urine.

Arterialized capillary blood specimens were obtained at zero time, and at 200,360, and 1,920 min for acid-base status and venous blood for electrolytes.

\section{Laboratory Methods}

The urinary net acid excretion (titratable acid minus bicarbonate plus ammonium) was measured by the titrimetric method $[5,10]$. All urine $\mathrm{pH}$ determinations were performed within an hour after collection. The net acid excretion was performed within 1-3 days on urine frozen previously [5]. Blood acid-base status was determined by the equilibration method of Astrup et al. [1], ${ }^{125}$ I-iothalamate clearance by the method of Cohen et al. [6], blood and urine electrolyte determinations by routine chemistry methods, and urine amino acid analysis performed on a Beckman AutoAnalyzer [17].

\section{Results}

Figure 1 depicts the minimal blood total $\mathrm{CO}_{2}$ at various times after ingestion of ammonium chloride. Although the mean total $\mathrm{CO}_{2}$ content for the two populations of transplant recipients fell within the standard deviation of the control subjects, a mild degree of metabolic acidosis existed when compared with normal subjects; 360 min after ammonium chloride ingestion severe metabolic acidosis was induced in all subjects. At the conclusion of the study period (1,920 min), the acidosis was corrected in the normal subjects, but persisted in the other three groups.

The renal tubular response to acute metabolic acidosis was tested by evaluating two interrelated tubular functions: (1) the ability of the distal tubule to maintain a steep pH gradient and (2) the tubular excretion of net acid (the sum of urinary titratable acidity minus bicarbonate pJus ammonium). The minimal urine $\mathrm{pH}$ corresponding to the time $\left(300-420\right.$ min after $\mathrm{NH}_{4} \mathrm{Cl}$ ingestion) when maximum system acidosis was documented is shown in Table II. There is little difference between the minimal urinary $\mathrm{pH}$ achieved by the normal and control subjects, whereas the minimal urinary $\mathrm{pH}$ is higher for both groups of allograft recipients 
Table II. Urinary data, 300-420 min after $\mathrm{NH}_{4} \mathrm{Cl}$ ingestion and corresponding to maximal systemic acidosis ${ }^{1}$

\begin{tabular}{l} 
Minimal pH \\
\cline { 3 - 6 }
\end{tabular}

TA : Titratable acidity; $\mathrm{NH}_{4}$ : ammonium; NAE : net acid excretion; GFR: glomerular filtration rate.

with $7 / 15$ of the cadaveric group but only $1 / 10$ of the live-related group showing urinary $\mathrm{pH}$ above 5.7 .

No urinary bicarbonate loss was detected and no abnormal amino acid loss was demonstrable.

The acidification mechanism in the four groups was further evaluated by simultaneous determination of urinary net acid excretion (Table II). At 300-420 min after ammonium chloride ingestion the mean urinary net acid excretion $\left(98 \mu \mathrm{Eq} / \mathrm{min} / 1.73 \mathrm{~m}^{2}\right.$ ) for the normal subjects is consistent with data in the literature [8, 9]. The net acid excretion of $76 \mu \mathrm{Eq} / \mathrm{min} / 1.73 \mathrm{~m}^{2}$ in the control subjects is significantly lower than that of the normal subjects $(P<0.05)$. The net acid excretion of the live-related donor allograft recipients was not significantly different from that of the cadaveric allograft recipients $(P>0.5)$. Both of the latter were significantly lower than values for the control group $(P<$ $0.05)$ and the normal subjects $(P>0.001)$.

The titratable acidity for both the live-related and cadaveric allograft recipients was lower than that of both the control and normal subjects. However, analysis of variance for control subjects, live-related, and cadaveric recipients indicated no significant difference between the three groups ( $F$ ratio 3.41 ). The values for urinary inorganic phosphorus excretion of live-related and cadaveric recipients were within the standard deviation of these values for control subjects (Table II).

Four of the five control subjects underwent unilateral nephrectomy 180-270 days (mean 218 days) before investigation and the fifth subject underwent unilateral nephrectomy 1,148 days before the study (Table I). The linear regression of the net acid excretion plotted against time postunilateral nephrectomy (Fig. 2) indicated no significant difference in net acid excretion
(NAE) with time. Regression studies for the live-related and cadaveric recipients gave similar results.

The ammonium excretion constituted 50-60\% of the total net acid excretion throughout the entire I,920 min of the study period without any definite variation (Fig. 2).

The net acid excretion throughout the entire 1,920 minutes of the study for all four groups (Fig. 3) indicates no significant difference in NAE between control subjects and the two groups of allograft recipients when the study period is continued for $1,920 \mathrm{~min}$. This is in contrast with the results if the study had been terminated at $600 \mathrm{~min}$ as described by Wrong and Davies [16] and Edelmann et al. [8]. In addition, Figure 3 shows that the net acid excretion of the normal subjects at 1,920 min was higher than that of the control group and of either allograft recipient group.

The analysis of variance on the glomerular filtration rates (Table II) resulted in an $F$ ratio of 1.56 , with 3 degrees of freedom between groups and 29 degrees of freedom within groups. This indicated that the glomerular filtration rate of the groups studied is different. This difference, however, is evident mainly between the normal subjects and the other three groups. The two allograft recipient groups fall within the standard deviation of the control group with an $F$ ratio of 0.46 .

Linear regression analysis of creatinine clearance against time in days postunilateral nephrectomy (control group) and days post-transplantation (both live-related and cadaveric recipient group) showed that the slope varied from -0.003 to 0.014 (Fig. 2). These data confirmed established observations that the glomerular filtration rates of unilateral nephrectomized subjects 
A

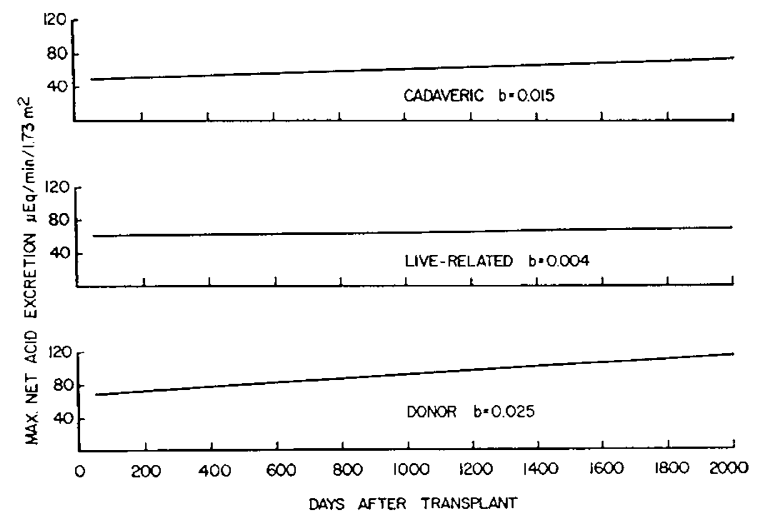

B
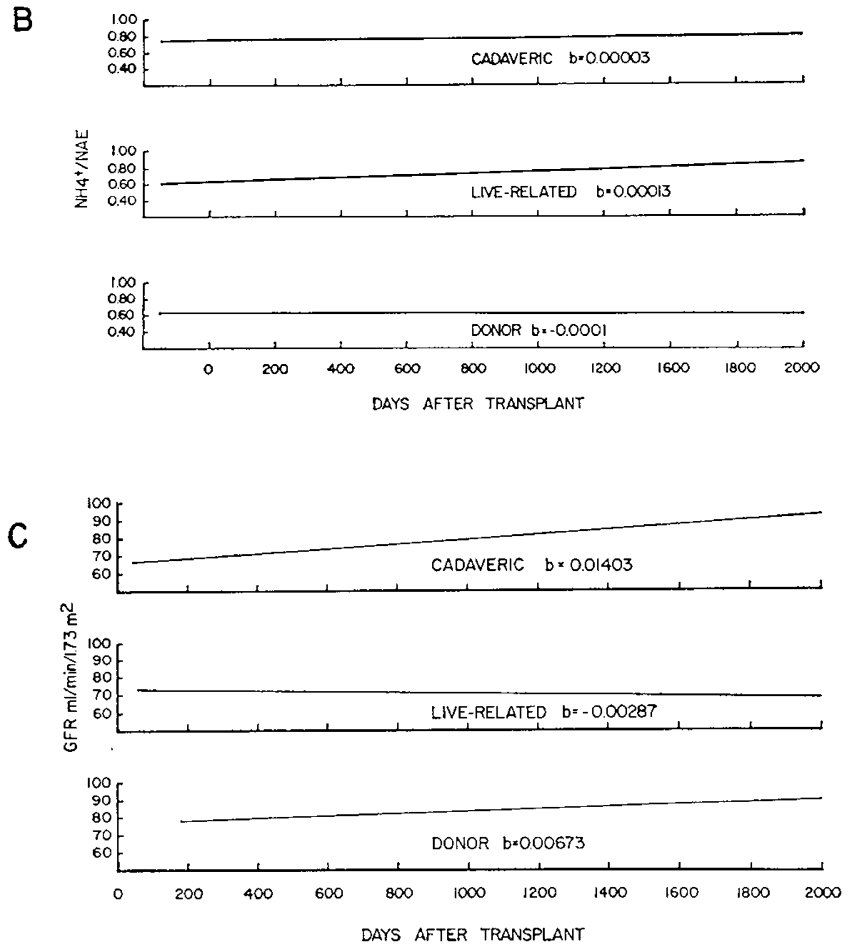

Fig. 2. A: Linear regression between maximal urinary net acid excretion to days post-transplantation; $B$ : linear regression between the ratio of ammonium over net acid excretion to days post-transplantation; $C$ : the relation of creatinine clearance to days after renal transplantation.

achieve $70-80 \%$ of normal after approximately 30 days $[7,9]$. Similar results were obtained for both recipient groups.

The net acid excretion per nephron by fractionation of the maximal net acid excretion with the corresponding glomerular filtration rate is shown in Table II. Analysis of variance for the four groups resulted in an $F$ ratio of 0.05 with 3 degrees of freedom between groups and 29 degrees of freedom within groups.
There was no significant difference between these groups $(P>0.95)$.

Urinary cultures were negative for bacteria in all subjects. Urinary amino acid excretion was normal in all subjects before and $4 \mathrm{hr}$ after ammonium chloride loading.

\section{Discussion}

The compensatory increase of the single donor or transplanted kidney to achieve $50-90 \%$ of the previous glomerular filtration rate has been amply documented $[7,9]$ and is reconfirmed in the present study (Table II).

The compensatory renal tubular acid excretion has received little investigative effort before [9]. The present data show that the maximal conpensatory changes occur in the first few months, after which the level of net acid excretion levels off (Fig. 2).

That the formation of ammonium is not maximally stressed by the short term ammonium chloride loading test is shown by the $\mathrm{NH}_{4}+/ \mathrm{NAE}$ ratio of $50-60 \%$ (Fig. 2). The data, therefore, are consistent with the objections raised by Relman [15] that a 3-day continuous oral load of ammonium chloride yields more definitive data on the mechanism of tubular ammonium formation. However, inasmuch as the present studies are for purposes of comparison, the data would imply that the renal tubular ammonium formation is comparable in all four groups.

A renal acidification defect in human cadaver kidney allografts is demonstrated in Table II. This finding is compatible with that of Better et al. [2, 3]. The present studies extend the observations of Better et al. [3] and demonstrate an acidification defect in live-related kidney allografts. Inasmuch as the total ischemia (warm plus cold) time in the cadaver allografts is 5 times that of the live-related allografts (Table III), a more severe degree of tubular damage and acidification defect is anticipated in the cadaver allografts. The absence of any differences in net acid excretion in these two groups tends to cast doubt on the hypothesis that the acidification defect is due to tubular necrosis secondary to the long ischemia time sustained at transplantation [3]. Unless one postulates that only the warm ischemia time is the important determinant in the development of tubular damage, it is difficult to explain the similarity of the acidification defect in both groups. The warm ischemia time is $13 \mathrm{~min}$ in cadaver allografts as compared with $6 \mathrm{~min}$ in live-related allografts (Table III). Inasmuch as these ischemia 

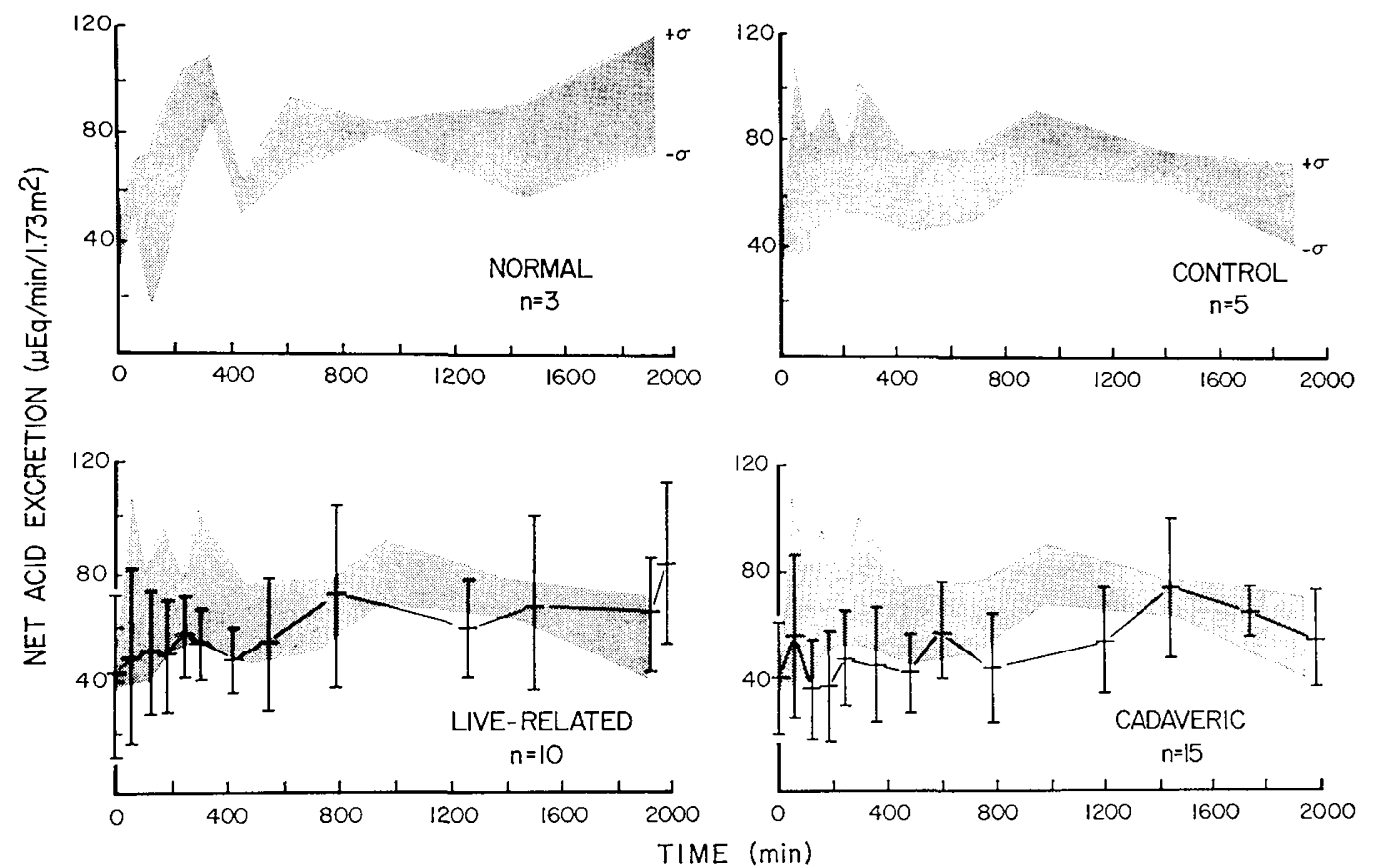

Fig. 3. The relation of net acid excretion to time (minutes) after ammonium chloride ingestion in normal, control (donor), live-related, and cadaveric kidney allograft recipients. Shaded area for control (donor) population transported to lower half of the figure for comparison with data of the two transplant populations.

times are comparably short, the degree of tubular damage may, therefore, be comparable.

We propose that the sequence of events is, most likely, tubular damage due to ischemia at the time of transplantation, proportionate lowering of GFR, and impaired acidification capacity. That the reduced GFR is the single important limiting factor in net acid excretion in the two transplant groups is demonstrated by the present data (Table II); when the low net acid excretions in the two transplant groups are factored by GFR, they become comparable with the control (donor) group as well as the normal group. This is evidence that each remaining nephron is excreting acid normally and is supportive of the "intact nephron" hypothesis [4].

However, despite the similarity illustrated above, it should be noted that there is a marked difference in urinary $\mathrm{pH}$ during acidosis between the two transplant groups: 7 out of 15 in the cadaver group but only 1 out of 10 in the live-related group have urinary $\mathrm{pH}$ above 5.7 (Table II). Thus, even though the mean values between the two groups are not statistically different, approximately $50 \%$ of the cadaveric kidneys have a marked defect in lowering urinary $\mathrm{pH}$, whereas approximately $10 \%$ only of the live-related allografts have such a defect. This would imply that cadaver allografts are more susceptible to a defect in lowering urinary $\mathrm{pH}$, even though the present studies show no direct correlation between ischemia time and the defect in lowering $\mathrm{pH}$.

With reference to Figure 3, it is of interest that the net acid excretion in the normal subjects is the same at $300-480 \mathrm{~min}$ as at 1,920 min. The corresponding mean value in the control group drops from 76 to $56 \mu \mathrm{Eq} /$ $\min / 1.73 \mathrm{~m}^{2}$, which then permits the slowly improving net acid excretion of the two transplant groups to catch up. Therefore, at 1,920 min, the net acid excretion for control (donor) group is comparable with the two transplant groups. This low level of net acid excretion is in distinct contrast to the normal subjects, which continue to put out net acid at a rate of 90 $\mu \mathrm{Eq} / \mathrm{min} / 1.73 \mathrm{~m}^{2}$. This difference in renal acidification may explain the complete correction of systemic metabolic acidosis in the normal subjects and the persistence of acidosis in the other three groups (Fig. 1).

Table III. Ischemic time of transplants

\begin{tabular}{lccc}
\hline & \multicolumn{3}{c}{ Ischemic time of transplants, min } \\
\cline { 2 - 4 } & Warm & Cold & Total \\
\hline $\begin{array}{c}\text { Live-related } \\
n=10\end{array}$ & $6.0 \pm 1.7$ & $38.0 \pm 5.1$ & $43.7 \pm 4.9$ \\
$\begin{array}{c}\text { Cadaveric } \\
n=15\end{array}$ & $13.0 \pm 10.8$ & $170.0 \pm 112.0$ & $189.0 \pm 107.0$ \\
\hline
\end{tabular}

${ }^{1}$ Excluded Belzer time 1,500 min $(n=1)$. 
The present studies offer evidence that the response of post-transplant allografts to acute acidosis is slow in comparison with that of normal subjects as well as single kidney (control) subjects (Fig. 3) because the maximal level of net acid excretion is achieved in normal and single kidney subjects between 300 and 400 min after ammonium chloride loading and on the whole, persists at that level for the duration of the study, whereas for the transplant subjects, maximal level of net acid excretion is achieved at $800 \mathrm{~min}$ and 1,400 min for the live-related and cadaveric allografts, respectively (Fig. 3).

In the absence of hypergammaglobulinemia [13], amphotericin B [12], or bicarbonaturia [14], it is reasonable to conclude from the present data that the renal acidification defect in transplant subjects is related to a reduced GFR secondary to the tubular damage sustained at transplantation.

\section{Summary}

The renal acidification capacities of patients with transplanted kidneys were tested by the short term acute ammonium chloride loading test and found to be lowered in comparison with the donor subjects with one remaining kidney as well as with normal subjects. It was also shown that the important limiting factor is the reduction in glomerular filtration rate in the patients with transplanted kidneys and that the maximal acid excretion occurred at a later point in time than it did with the donor subjects.

The data also showed a marked difference in the ability to lower urine $\mathrm{pH}$ to below 5.4 between the cadaveric and live-related transplants. Fifty percent of the cadaveric allografts had an inability to lower urine $\mathrm{pH}$ below 5.4 as compared with only $10 \%$ of the liverelated allografts. This implied that the former type of allografts were more prone to an acute acid load.

\section{References and Notes}

1. Astrup, P., Jorgensen, K., Siggard-Andersen, A., and Engel, K.: The acid-base metabolism: A new approach. Lancet, $i$ : I035 (1960).

2. Betrer, O. S., Alroy, G. G., Ghaimovitz, G., and Sisman, Z.: Spontaneous remission of the defect in urinary acidification after cadaver kidney homotransplantation. Lancet, $i$ : 110 (I970).

3. Betrer, O. S., Chaimovitz, C., Naveh, Y., Stein, A., Nahir, A. M., BonjrLaI, B., AND ErLik, D.: Syndrome of incomplete renal tubular acidosis after cadaver kidney transplantation. Ann. Int. Med., 71: 39 (1969).

Copyright (C) 1973 International Pediatric Research Foundation, Inc.
4. Bricker, N. S.: On the meaning of the intact nephrone hypothesis. Amer. J. Med., 46: 1 (1969).

5. Chan, J. C. M.: The rapid determination of urinary titratable acid and ammonium and evaluation of freezing as a method of preservation. Clin. Biochem., 5: 94 (1972).

6. Cohen, M. L., Smith, F. G., JR., Mindell, R. S., ANd Vernier, R. L.: A simple, reliable method of measuring glomerular filtration rate using single, low dose sodium iothalamate $I^{131}$. Pediatrics, 43: 407 (1969).

7. Donadio, J. V., Jr., Farmer, C. D., Hunt, J. C., Taule, W. N., Hallenbeck, G. A., and Shorter, R. G.: Renal function in donors and recipients of renal allotransplantation. Ann. Int. Med., 66: 105 (1967).

8. Edelmann, C. M., JR., Borchis, H., Rodriguez-Soriano, J., AND STARK, H.: The renal response of children to acute ammonium chloride acidosis. Pediat. Res., 1: 452 (1967).

9. Herdman, R. C., Michael, A. F., Vernier, R. L., Kelly, W. D., AND GOOD, R. A.: Renal function and phosphorus excretion after human renal homotransplantation. Lancet, $i$ : 121 (1966).

10. Jorgensen, K.: Titrimetric determination of the net excretion of acid-base in urine. Scand. J. Clin. Lab. Invest., 9: 287 (1957).

11. Massry, S., Preuss, H. G., Maher, J. F., and Schretner, G. E.: Renal tubular acidosis after cadaver kidney homotransplantation. Amer. J. Med., 42: 284 (1967).

12. McCurdy, D. K., Frederic, M., and Elkinton, J. R.: Renal tubular acidosis due to amphotericin B. New Engl. J. Med., 278: 124 (1968).

13. Morris, R. C., ANd Fundenberg, H. H.: Impaired renal acidification in patients with hypergammaglobulinemia. Medicine, 46: $57(1967)$.

14. Prrts, R. F.: Physiology of the Kidney and Body Fluids. (Year Book Medical Publishers, Inc., Chicago, 1968).

15. RELMAN, A. S.: Renal acidosis and renal excretion of acid in health and discase. Advan. Int. Med., 12: 295 (1964).

16. Wrong, O., and Davies, H. E. F.: The excretion of acid in renal disease. Quart. J. Med., 28: 259 (1969).

17. Beckman Instruments, Inc., Fullerton, Calif.

18. All procedures have been performed in accordance with the provisions set forth in the Declaration of Helsinki.

19. The authors wish to thank Potter Chang, Ph.D., and Petex Dukes, Ph.D., for statistical advice, Rebecca Ma, B.A., Doris Ekker, B.A., and Jeane Gullihur, B.A., for expert technical assistance, and the nurses of the Clinical Research Center at Children's Hospital of Los Angeles for meticulous metabolic collections. The help of Kenneth N. F. Shaw, Ph.D., in obtaining the amino acid analysis is much appreciated.

20. This research was presented in part at the Society for Pediatric Research, 42nd Annual Meeting, Washington, D.C., May 22-26, 1972.

21. This research was supported by a grant from the Southern California Kidney Foundation, Grant no. RR-86 from the General Clinical Research Centers Program of the Division of Research Resources, National Institutes of Health, and Contract no. HSM 110-71-270 from the HSMHA, Department of Health, Education and Welfare.

22. Requests for reprints should be addressed to: JAires C. M. CHAN, M.D., Children's Hospital of Los Angeles, P.O. Box 54700, Terminal Annex, Los Angeles, Calif. 90054 (USA).

Printed in U.S.A. 